\title{
Correction to: The interplay of national distances and regional networks: Private equity investments in emerging markets
}

Santiago Mingo ${ }^{1}$,

Francisco Morales ${ }^{2}$ and

Luis Alfonso Dau ${ }^{3}$

${ }^{7}$ Escuela de Negocios, Universidad Adolfo Ibáñez, Av. Diagonal Las Torres 2640 - Peñalolén, 7941169 Santiago, Chile; ${ }^{2}$ Leeds School of Business, University of Colorado-Boulder, Boulder, CO, USA; ${ }^{3} D^{\prime}$ Amore-McKim School of Business, Northeastern University, Boston, MA, USA

\section{Correspondence:}

$S$ Mingo, Escuela de Negocios, Universidad Adolfo Ibáñez, Av. Diagonal Las Torres 2640 - Peñalolén, 7941169 Santiago, Chile. Tel: +56 (2) 2331-1692; e-mail: santiago.mingo@uai.cl
Journal of International Business Studies (2018) 49, 657.

https://doi.org/10.1057/s41267-0 I8-0145-9

\section{CORRECTION TO: JOURNAL OF INTERNATIONAL BUSINESS STUDIES (2018) https://doi.org/10.1057/s41267-017-0141-5}

The licence for this article has been modified since online publication. This article is now available under a CC-BY licence. We apologise to the author that this was not applied before first publication. No other changes have been made to the content. 